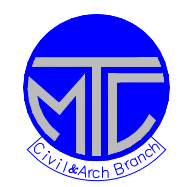

\title{
ICCAE
}

Military Technical College

Kobry Elkobbah, Cairo, Egypt 7hㅡ International Conference

On Civil \& Architecture

Engineering

\section{FINITE ELEMENT ANALYSIS OF CRATER FORMATION IN CLAY SOILS}

\author{
Nabil NAGY ${ }^{1}$, Mostafa MOHAMED ${ }^{2}$ and Jess BOOT ${ }^{3}$
}

\begin{abstract}
Numerical studies of craters produced by explosions on or underneath the ground surface are scarce An ability to predict the anticipated size of crater is crucial to identify the corresponding damage that might be caused by a given explosive charge, or to assess the magnitude of the charge if this was not known. In this paper, a non-linear dynamic numerical analysis of the explosion phenomena in clay soils associated with different amounts of TNT explosive charge is performed using the ABAQUS/Explicit finite element code. To validate the numerical procedure and material constitutive models used in the present work, a comparison with relatively small scale experiments is first performed. The results obtained illustrate that an agreement between numerical and experimental results is reasonable. Further numerical investigations have been carried out for the crater dimensions created from bigger amounts of TNT charges. A study of the influence of soil density on the crater dimensions is then undertaken. Based on the obtained numerical results, a new prediction equation is proposed for the crater dimensions as a function of the explosive charge considered. This equation represents the approximation of the numerical results by least squares fitting. It was found that variation of soil density could cause a change of up to $4 \%$ in the crater diameter. However, it will be necessary to investigate variation of all the soil parameters before more generalized conclusions can be made.
\end{abstract}

Keywords: crater - surface blast - finite element analysis - soil-blast interaction

1 Lecturer in Geotechnical Engineering Civil Eng. Department, Military Technical Collage Cairo,EGYPT, nabilmnagy@yahoo.com

2 Lecturer in Geotechnical Engineering, School of Engineering, Design and Technology, University of Bradford, Bradford, UK. Email: m.h.a.mohamed@bradford.ac.uk

${ }^{3}$ Reader in Structural Engineering, School of Engineering, Design and Technology, University of Bradford, Bradford, UK. 


\section{INTRODUCTION}

Studies of craters produced by explosions above or underneath the ground surface are rarely found in the open technical literature. Most reports are confidential and their access is limited to government agencies. Much of the information about explosively formed craters found in the literature is based on experimental data. Numerical studies were very limited until recently. An ability to predict the anticipated size of crater is crucial to identification of the corresponding damage that might be caused by a given explosive charge, or to assess the magnitude of the charge if this is not known. Following the recent explosive attacks around the world there is a clear need for extensive studies of the explosive effects on soils and crater formations. Investigating and studying the crater formation is a valid means of studying the soil-blast interaction phenomena (Persson et al., 1994). Studying the crater formations produced by explosions will give a good means for estimating the explosive charge (mass of explosive) used and give good data about the explosion process. The mechanism of crater formation is complex and is associated with the dynamic physical properties of air, soil and explosive. Even very carefully controlled cratering tests produce deviations in the crater dimensions measured of at least $10 \%$, while differences of as much as $30 \%$ to $40 \%$ are common (Bull and Woodford, 1998).

Numerical investigations of crater formation were very rare until recently. Different numerical codes can be used to study the problem of crater formation. For example using the hydrocode AUTODYNA-2D, Ambrosini et al., (2004) investigated the crater formation using the pure Euler formulation to model the soil and air regions. For the strength effects, the soil was modeled using an elasto-plastic Mohr Coulomb yield criterion. Kanarachos and Provatidis, (1998) used the finite element code "ABAQUS" to study the influence of blast explosions on soils and buried structures. The explosion was simulated as an impulsive pressure of triangular shape, but only limited data for crater formation was presented. Iturrioz and Riera, (2001) investigated numerically the crater dimensions using a discrete element method (DEM). The soil was modelled as a brittle material with specified elastic and fracture properties. Comparison between numerical and experimental results demonstrates that DEM produces reasonable results for the crater formation. However, DEM generates large number of degrees of freedom, and consequently only a very limited numerical study was presented. Consequently further investigations are required to study the effects of using alternative soil models and different locations and magnitudes of charge. Thus it seems sensible to conclude that there is still a need for further investigations considering a fully coupled model for the interaction between air-soil-explosion.

In this paper the ABAQUS/Explicit finite element (FE) code is used which incorporates several useful features in the present context. The ALE (Arbitrary Lagrange Euler Coupling - Hu and Randolph, 1998) formulation is invoked to overcome the major problems associated with the large mesh distortion encountered in crater formation without recourse to Smooth Particle Hydrodynamics (Liu and Liu, 2003). In addition non-linear behaviour of the soil is included using a Drucker-Prager Cap model, which in principle is capable of representing a wide range of soil behaviours. The prime objective 
of the paper is to report the initial results obtained using this representation of crater formation in clay.

The explosive charges used in this paper were chosen to be within the mass range which might be used in any terrorist attacks against important buildings. These terrorist attacks commonly take place on the ground surface. The range of explosive charge (mass) experienced in such attacks was discussed by Elliot et al., (1992) and also represents the range of the surface mine charges that is normally used in military operations.

In order to validate not only the material models and corresponding properties but also the analysis procedures; a validation stage is initially conducted by comparing the results of a series of physical tests undertaken by Ambrosini et al., (2002) with those obtained from a detailed numerical modelling of the same physical problem. This enables calibration of the model and material parameters. A better understanding of the explosion phenomena is being gradually gained by combining the results from physical experiments and numerical modelling (Braid and Bergeron, 2001 and Fairlie and Bergeron, 2002). A numerical investigation of the crater formation obtained using different amounts of charge located on the soil surface is then undertaken. TNT Charges from 20 to $640 \mathrm{~kg}$ are used. In addition a study of the influence of soil properties on the crater dimensions is performed. From the numerical results obtained, an empirical equation is proposed for the prediction of crater diameter resulting from the explosive charges considered. This equation represents the approximation of the numerical results by least squares fitting.

\section{CRATER DIMENSIONS}

The shape of the crater created by an explosive charge positioned on or below the ground level is shown in cross section in Figure 1. The crater dimensions are based on the definitions of Kinney and Graham (1985) and Cooper (1997) which are used in this study. Figure 1 also shows the characteristic features of a crater produced by the explosion in cross-section. The explosion is thus considered to produce four regions of the crater. The first is the plastic zone where the soil has been deformed and compressed to higher than normal density. The second region is the rupture region, which is crushed and damaged because of the explosion. Beyond this is the third region, which is the fallback zone, where the ejected soil returns back to the cavity, hiding the true (original) crater boundary and forming the boundary of the apparent crater. The final region is the ejecta region that forms the outer portion of the crater edge. In Figure 1, $D$ is the apparent diameter of the crater, $D_{r}$ is the true crater diameter and $\mathrm{d}$ is the apparent depth of the crater. 


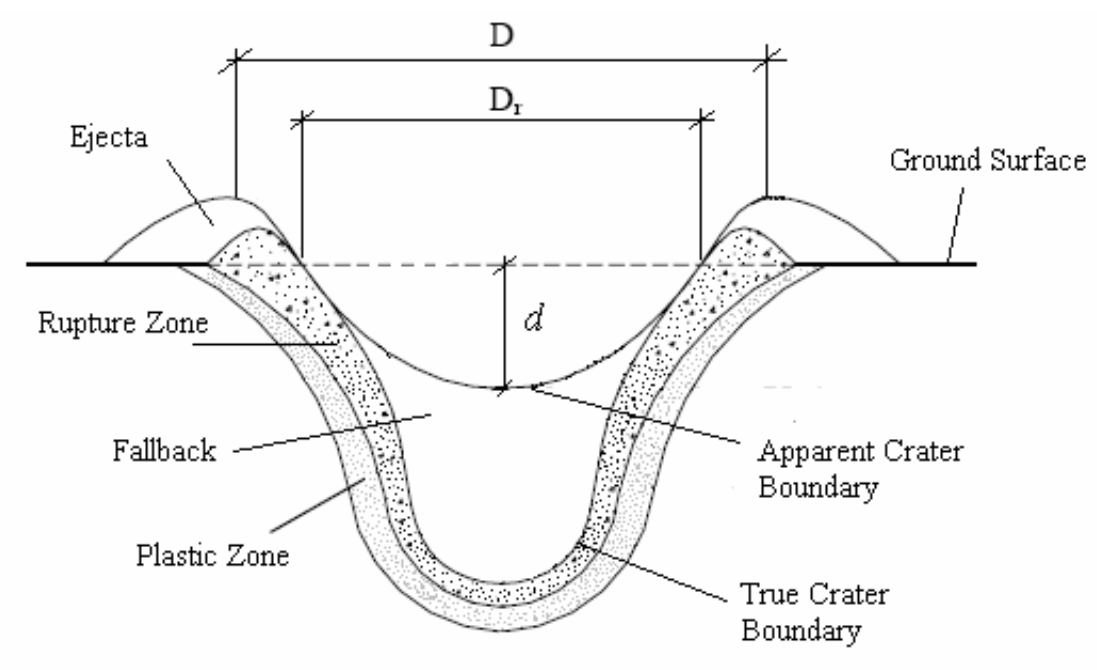

Figure 1. Cross sectional dimensions of a typical crater

\section{FINITE ELEMENT MODEL OF CRATER FORMATION}

\section{Numerical mesh}

In this paper, the non-linear finite element program ABAQUS/Explicit is used to undertake a two-dimensional (2D) axisymmetric analysis of the problem as shown in Figure 2. The Arbitrary Lagrange Euler Coupling formulation (ALE) is used in the analysis to eliminate the distortion of the mesh under high deformation $\mathrm{CHu}$ and Randolph, 1998). The overall geometric model is divided into three different regions representing the soil, air and explosive materials. A convergence study involving mesh refinement, appropriate selection of element types and simulation of the infinite boundaries was initially performed; hence the optimum meshes were identified for the soil, explosive charge (TNT) and the air, as shown in Figure 2.

The soil region is represented by 4-node bilinear axisymmetric quadrilateral, reduced integration, elements (CAX4R). Smaller elements are used in the higher stress region i.e. near the explosion, with progressively larger elements as the stresses reduce, as shown in Figure 2. Symmetry boundary conditions are applied along the axis of symmetry by restraining the displacement in the radial direction $(u=0.0)$. The 4-node, axisymmetric, infinite elements (CINAX4) are used to provide quiet boundaries at the right side and bottom boundaries to the soil mesh. In this manner the ability of the elements to transmit energy out of the finite element mesh without trapping or reflecting it is optimized by simulating a boundary at infinity (ABAQUS Theory Manual, 2005).

In order to obtain a good refinement of the air mesh, and to avoid high distortion errors, the air region is represented by an assemblage of 3-node linear axisymmetric triangular elements (CAX3) in the near field region to the charge. The far field air region is again represented by 4-node bilinear axisymmetric quadrilateral elements (CAX4R), with infinite elements (CINAX4) providing the quiet boundaries at the right hand side and top 
of the air region. The explosive material zone is meshed by 4-node bilinear axisymmetric quadrilateral, reduced integration elements (CAX4R). The size of this zone and number of elements in it depend on the magnitude of the explosive charge (i.e. the charge mass).

The explosive charge is varied from $1 \mathrm{~kg}$ to $640 \mathrm{~kg}$ of TNT and the mesh dimensions varied accordingly. For small charges in the range $1-20 \mathrm{~kg}$, a mesh of $12 \mathrm{~m} \mathrm{x} 12 \mathrm{~m}$ is used for both the soil and air regions whilst for charges of $40 \mathrm{~kg}$ and more meshes of 30 $\mathrm{m} \times 30 \mathrm{~m}$ is used.

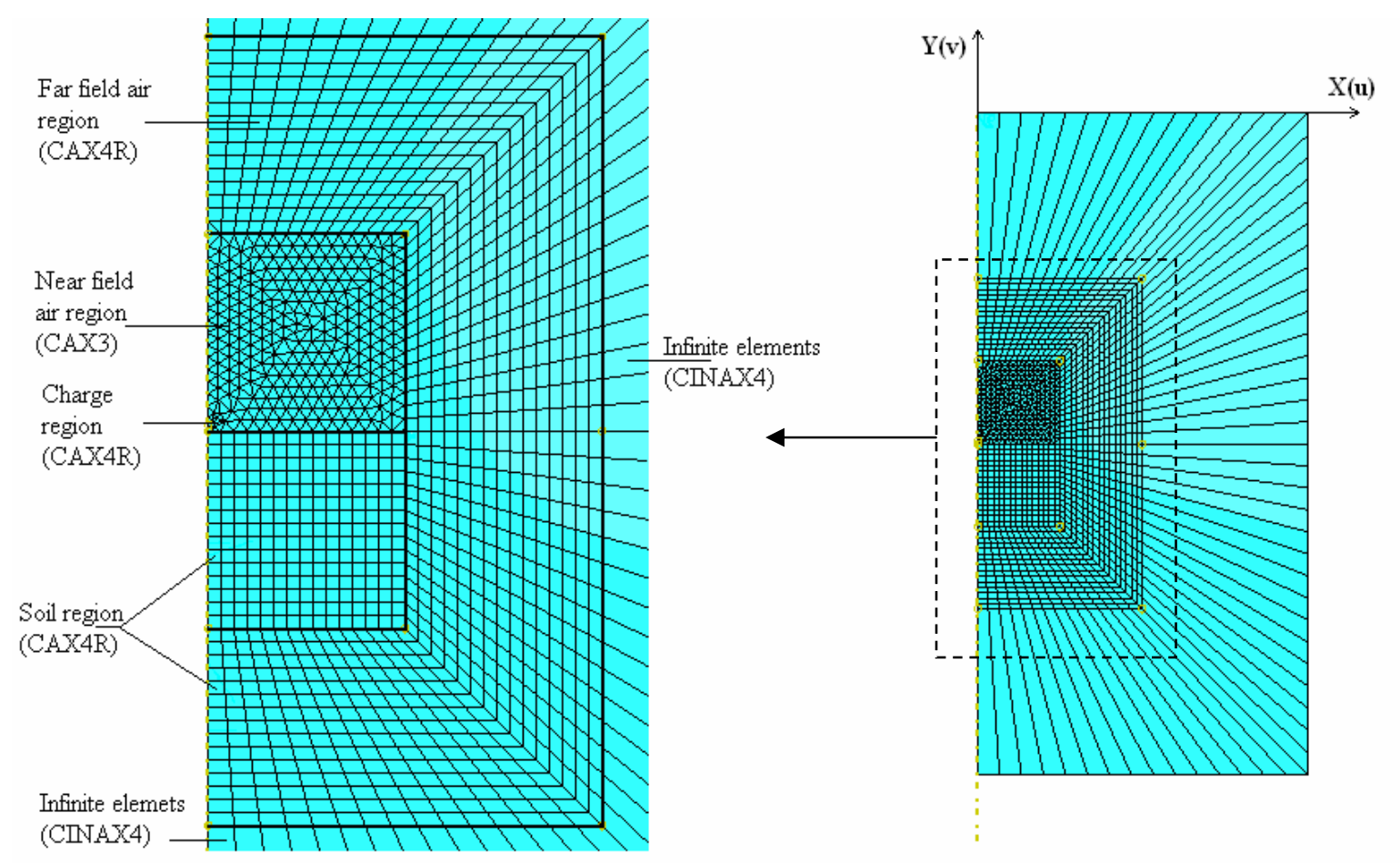

Figure 2. Mesh for the axisymmetric model

\section{Material models}

\section{Soil model}

The soil is considered as a clay soil whose behaviour is modelled by an elasto-plastic Drucker - Prager Cap model. The Drucker-Prager-Cap model was originally developed to predict the plastic deformation of soils under compression (Drucker, 1952; Mizuno and Chen, 1990). It consists principally of two intersecting segments: a shear failure segment $F s$ and a cap segment $F c$ which provides an inelastic hardening mechanism to account for plastic compaction and helps to control volume dilatancy when the material yields in shear. A transition segment $F_{t}$ has been introduced to provide a smooth surface between the shear failure surface and cap segment. Figure 3 shows the segments in the $p-q$ plane where $p$ is the equivalent pressure stress and $q$ is the Misses equivalent stress.

The two stress invariants $p$ and $q$ can be defined as: 


$$
\begin{gathered}
p=-\frac{1}{3}\left(\sigma_{1}+\sigma_{2}+\sigma_{3}\right) \\
q=\sqrt{\frac{3}{2}(S: S)}
\end{gathered}
$$

where; $\sigma_{1}, \sigma_{2}$ and $\sigma_{3}$ are the principal stresses. trace is a $(n \times n)$ matrix function defines the sum of the elements on the main diagonal (the diagonal from the upper left to the lower right of the matrix), (:) denotes the scalar product and $\mathrm{S}$ is the stress deviator, defined by $S=\sigma+p I$. where; $I$ is the identity matrix. The shear failure segment in the Drucker-Prager Cap model provides a criterion for the occurrence of shear flow, which is dependent upon the cohesion $d$ and the angle of internal friction $\beta$ of particulate materials according to the Mohr-Coulomb hypothesis:

$$
F_{s}=q-p \tan \beta-d=0
$$

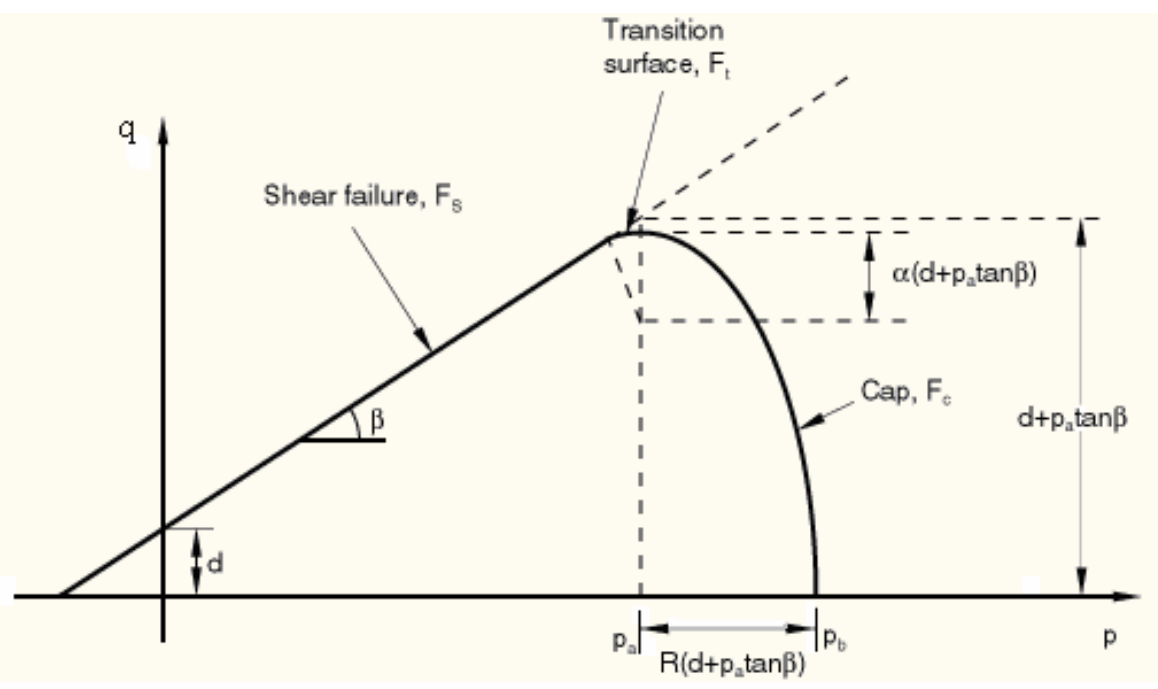

Figure 3. The Drucker - Prager Cap model (ABAQUS Theory Manual, 2005)

The cap segment, which intersects the equivalent pressure stress axis, is an elliptical curve with constant eccentricity in the $p-q$ plane as given by:

$$
F_{c}=\sqrt{\left(p-p_{a}\right)^{2}+\left(\frac{R_{t}}{1+\alpha-\alpha / \cos \beta}\right)^{2}}-R\left(d+p_{a} \tan \beta\right)=0
$$

where $R$ and $\alpha$ are parameters determining the shape of the cap segment and the smooth transition surface between the shear failure segment and the cap segment, respectively. $p_{a}$ 
is an evolution parameter representing the hardening or softening driven by the volumetric plastic strain, and is given by:

$$
p_{a}=\frac{p_{b}-R d}{1+R \tan \beta}
$$

where $\mathrm{pb}$ is the hydrostatic pressure yield surface that defines the position of the cap. $\mathrm{pb}$ is generally assumed to be dependent upon the volumetric inelastic strain $\varepsilon_{v o l}^{i n}$. This dependence controls the hardening or softening of the cap segment; volumetric plastic compaction results in hardening, while volumetric plastic dilation develops softening. In order to ensure that the primary feature of the Drucker-Prager Cap model is not significantly modified by the introduction of the transition segment and for the sake of numerical implementation, the transition segment is always kept relatively small by restricting the parameter $\alpha$ to typical values of 0.01 to 0.05 . The transition segment is given by:

$$
F_{t}=\sqrt{\left(p-p_{a}\right)^{2}+\left[q-\left(1-\frac{\alpha}{\cos \beta}\right)\left(d+p_{a} \tan \beta\right)\right]^{2}}-\alpha\left(d+p_{a} \tan \beta\right)=0
$$

Full calibration of the model described above requires triaxial test data. In the numerical analysis of this paper, the soil properties included are obtained from the actual properties of the clay soil used in the physical tests presented by Ambrosini et al., (2002). However, these properties are not sufficient to fully specify the parameters required to define a Drucker-Prager Cap model. Therefore, the parameters required to define the cap plasticity model are determined by a best match between the material properties obtained experimentally by Ambrosini et al., (2002) and those quoted in the ABAQUS Example Manual (2003). The soil properties and the corresponding cap plasticity parameters used are given in Table 1.

Table 1. Material properties of the clay soil

\begin{tabular}{|c|c|}
\hline Parameter & Value \\
\hline Young's modulus $(\mathrm{E})$ & $494 \mathrm{MPa}$ \\
\hline Poisson's ratio $(v)$ & 0.17 \\
\hline Density $(\rho)$ & $1920 \mathrm{~kg} / \mathrm{m}^{3}$ \\
\hline Material cohesion $(\mathrm{d})$ & $1.38 \mathrm{MPa}$ \\
\hline Material angle of friction $(\beta)$ & $40.4^{\circ}$ \\
\hline Cap eccentricity parameter $(\mathrm{R})$ & 0.3 \\
\hline Initial cap yield surface position $\left(\varepsilon_{\mathrm{v}}\right)$ & 0.02 \\
\hline Transition surface radius parameter $(\alpha)$ & 0.01 \\
\hline & $2.75 \mathrm{MPa}, 0.00$ \\
Cap hardening behaviour & $4.83 \mathrm{MPa}, 0.02$ \\
(Stress, plastic volumetric strain) & $5.15 \mathrm{MPa}, 0.04$ \\
& $6.20 \mathrm{MPa}, 0.08$ \\
\hline
\end{tabular}




\section{Air model}

The air is modelled using the ideal gas equation of state. This is one of the simplest forms of equation of state for gases (Hodge and Koenig, 1995) which is implemented in ABAQUS and can be written in the form:

$$
P+P_{A}=\rho R\left(\theta-\theta^{Z}\right)
$$

where $P_{A}$ is the ambient pressure, $R$ is the gas constant, $\theta$ is the current temperature, and $\theta \mathrm{Z}$ is the absolute zero on the temperature scale being used. In general, the value $R$ for any gas can be estimated as a function of state (e.g., pressure or temperature). The ideal gas approximation is adequate in any region where this value is constant. At constant volume the specific heat $\mathrm{C}_{\mathrm{V}}$ should be specified for an ideal gas. $\mathrm{C}_{\mathrm{V}}$ is related to the specific heat at constant pressure, $\mathrm{C}_{\mathrm{P}}$, by the following equation.

$$
R=C_{P}-C_{V}
$$

In all analyses the air around the explosion area has been modelled as an ideal gas with the following properties presented by Batchelor (2000). Table 2 presents the air model properties.

Table 2. Material Properties of Air

\begin{tabular}{|c|c|}
\hline Parameter & Value \\
\hline Gas constant, $R$ & $287.1 \mathrm{~J} / \mathrm{Kg} / \mathrm{K}$ \\
\hline The ambient pressure $P_{A}$ & $101.36 \mathrm{KPa}$ \\
\hline The specific heat & $717.98 \mathrm{~J} / \mathrm{Kg} / \mathrm{K}$ \\
\hline The reference density & $1.225 \mathrm{Kg} / \mathrm{m}^{3}$ \\
\hline The reference temperature & $15^{\circ} \mathrm{C}$ \\
\hline
\end{tabular}

In view of the fact that the air is a gaseous material and has no ability to support either shear stresses or negative pressures, no strength or failure relations are mandatory for this material (Grujicic et al., 2006).

\section{Charge model}

The charge is modelled using the Jones-Wilkens-Lee (JWL) equation of state. This simulates the pressure generated by expansion of the detonation product and chemical energy of a chemical explosive (Lee et al., 1968; Lee et al., 1973). This model has been widely used in engineering applications. The JWL equation of state can be written in terms of the initial energy per unit mass, $E_{m 0}$ as follows (ABAQUS Analysis Manual, 2004).

$$
\mathrm{P}=A\left(1-\frac{\omega \rho}{R_{1} \rho_{0}}\right) \exp \left(-R_{1} \frac{\rho_{0}}{\rho}\right)+B\left(1-\frac{\omega \rho}{R_{2} \rho_{0}}\right) \exp \left(-R_{2} \frac{\rho_{0}}{\rho}\right)+\frac{\omega \rho^{2}}{\rho_{0}} E_{m 0}
$$


where $A, B, R_{1}, R_{2}$ and $\omega$ are material constants which for many common explosives have been determined from dynamic experiments. $\rho_{0}$ is the density of the explosive and $\rho$ is the density of the detonation products. The initial relative density $\left(\rho / \rho_{0}\right)$ used in the JWL equation is assumed to be unity, therefore nonzero values of initial specific energy Em0 should be specified. In the analyses the TNT explosive charges have been modelled by The JWL equation of state with properties as presented by Zhongqi et al., (2004) and in the ABAQUS Example Manual (2005). The parameters for the TNT are listed in Table 3.

Although this model does not simulate fallback due to being a continuum analysis, formation of the crater rapture and plastic zones, see Figure 1, are correctly simulated (Kanarachos and Provatidis, 1998). If it is required to model fallback, an analysis incorporating smooth particle hydrodynamics should be used (Wang, 2001).

Table 3. JWL parameters used for modelling TNT explosive

\begin{tabular}{|c|c|}
\hline Parameters & Value \\
\hline Detonation wave speed, $C_{d}$ & $6930 \mathrm{~m} / \mathrm{s}$ \\
\hline $\mathrm{A}$ & $373.8 \mathrm{GPa}$ \\
\hline $\mathrm{B}$ & $3.747 \mathrm{GPa}$ \\
\hline $\mathrm{R}_{1}$ & 4.15 \\
\hline $\mathrm{R}_{2}$ & 0.9 \\
\hline$\omega$ & 0.35 \\
\hline The density of the explosive, $\rho_{0}$ & $1630 \mathrm{Kg} / \mathrm{m}^{3}$ \\
\hline Initial specific energy $E_{m 0}$ & $3.63 \mathrm{Joule} / \mathrm{kg}$ \\
\hline
\end{tabular}

\section{COMPARISON BETWEEN NUMERICAL AND EXPERIMENTAL RESULTS}

Numerical formation of the whole crater for the case of $10 \mathrm{~kg}$ of TNT located on the soil surface is shown in Figure 4 at different times after the explosion. The Figure also shows the Von Misses stresses developed in the soil and the crater progression from $4 \mathrm{~ms}$ to 12 ms. It can be seen that immediately after detonation the value of stress is high in the region close to the explosion-soil interface. With time, the stress wave propagates into the soil mass resulting in an attenuation of the stresses. This results in the formation of rupture and plastic zones as described in Figure 1. Also shown in Figure 4 is the ejecta whose height increases with time after explosion. The maximum height of the ejecta is reached at $12 \mathrm{~ms}$ after the explosion. The results of crater formation after $12 \mathrm{~ms}$ provide no additional information, which indicates that $12 \mathrm{~ms}$ is sufficient for the completion of crater formation.

In order to verify the finite element analysis, a comparison with experimental results is first carried out. The results of a series of tests performed by (Ambrosini et al., 2002) with different amounts of explosive from $1 \mathrm{~kg}$ to $10 \mathrm{~kg}$ on the soil surface are used to calibrate the material and model parameters. The explosive charges used in these tests were Gelamon 80 a NG (Nitro Glycerine) based gelatinous explosive theoretically 
equivalent in mass to $80 \%$ of TNT. In order to perform a validation and comparative analysis the mass of explosive was defined by TNT equivalent mass. In order to get the corresponding mass for any other kinds of explosive, the concept of TNT equivalence stated by Formby and Wharton, (1996) and Smith and Hetherington, (1994) can be used. The results of the validation exercise are presented in Table 4.

The mean value of the numerical results is $92.7 \%$ of the equivalent experimental results. It can be seen therefore that there is good agreement between the numerical results and the corresponding experimental ones, which enables us to be confident not only in the material models and material properties but also in the mesh design and analysis procedures. Thus the proposed analysis has enabled accurate representation of all aspects of the crater formation except the ejecta (see Fig 4). This is due to the large mesh distortion associated with a continuum model, and can be overcome using Smooth Particle Hydrodynamics (Liu and Liu, 2003).

Table 4 Numerical results for crater diameter and comparison with the equivalent experimental results

\begin{tabular}{|c|c|c|c|c|}
\hline $\begin{array}{c}\text { Case } \\
\text { no. }\end{array}$ & $\begin{array}{c}\text { Mass of TNT } \\
\text { charge } \\
\text { (kg) }\end{array}$ & $\begin{array}{c}\text { Experimental results } \\
\text { (Ambrosini et al., } \\
2002) \\
D_{r}(\mathrm{~m}) \\
\end{array}$ & $\begin{array}{c}\text { Numerical } \\
\text { Results } \\
D_{r}(\mathrm{~m})\end{array}$ & Num./Exp.\% \\
\hline 1 & 1 & 0.58 & 0.502 & $86.6 \%$ \\
\hline 2 & 2 & 0.74 & 0.72 & $97.3 \%$ \\
\hline 3 & 4 & 0.84 & 0.88 & $104.0 \%$ \\
\hline 4 & 7 & 1.48 & 1.226 & $82.8 \%$ \\
\hline 5 & 10 & 1.56 & 1.45 & $92.9 \%$ \\
\hline
\end{tabular}

These results are presented graphically in Figure 5 with the true crater diameter $D_{r}$ plotted as a function of the cubic root of the explosive mass $M$. It can again be seen that there is a good agreement between the numerical and experimental results. The numerical results are also used to obtain a best-fit line passing through the origin, which can be represented by the following equation:

$$
D_{r}=0.6172 M^{1 / 3}
$$

The R-Square value for this line is 0.968 . From Figure 5, it can be seen that the line is also close to the experimental results again confirming good agreement between numerical and experimental results.

Kinney and Graham (1985) undertook a statistical study of two hundred surface explosion tests to obtain an equation for crater diameter $D_{r}$, in metres, in terms of explosive mass M, in kilograms TNT. Their equation is stated as follows: 

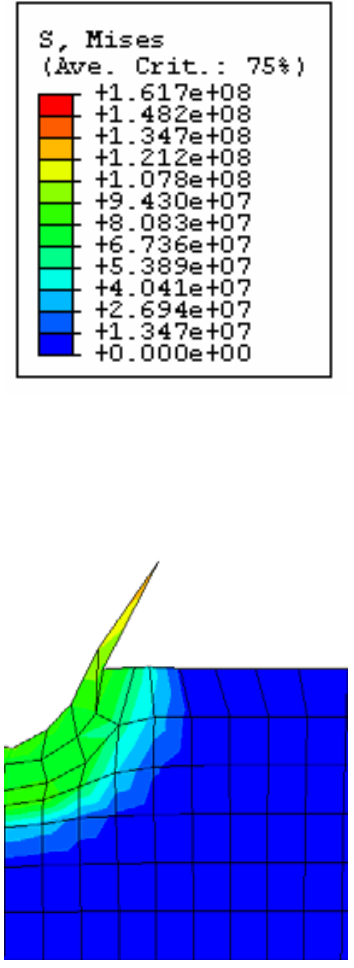

(c) $\mathrm{t}=7 \mathrm{~ms}$

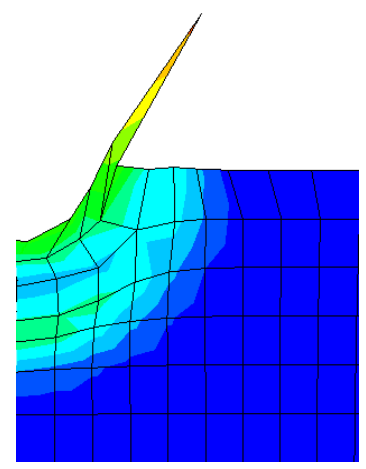

(f) $\mathrm{t}=10 \mathrm{~ms}$

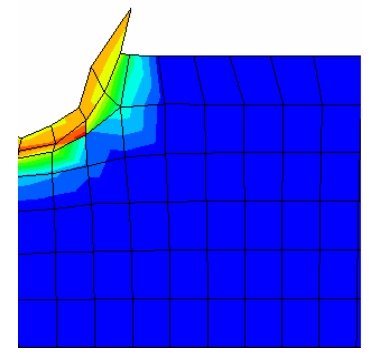

(a) $\mathrm{t}=4 \mathrm{~ms}$

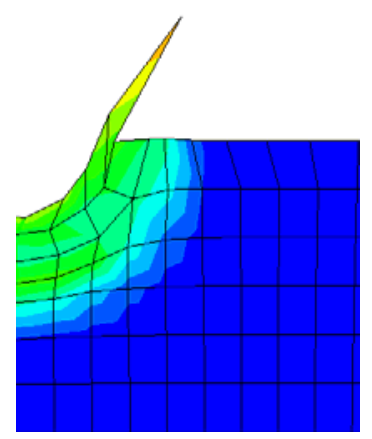

(d) $\mathrm{t}=8 \mathrm{~ms}$

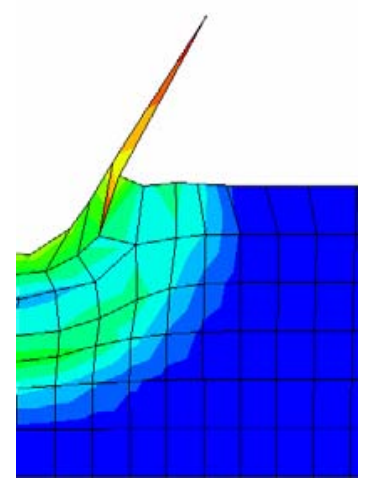

(g) $\mathrm{t}=11 \mathrm{~ms}$

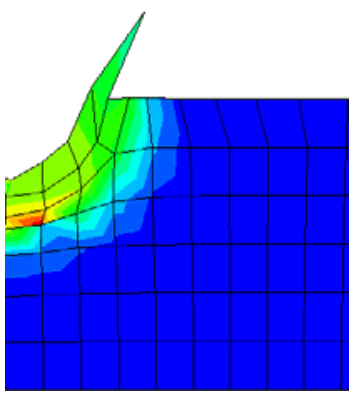

(b) $\mathrm{t}=6 \mathrm{~ms}$

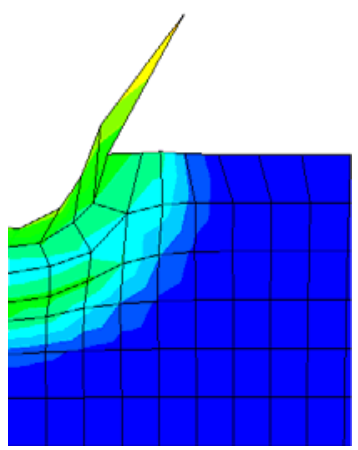

(e) $\mathrm{t}=9 \mathrm{~ms}$

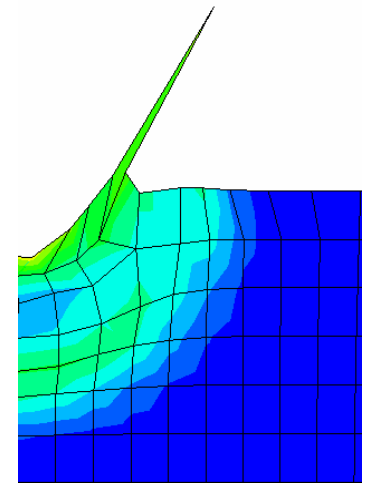

(h) $\mathrm{t}=12 \mathrm{~ms}$

Figure 4 Crater formation of surface 10Kg TNT explosion

$$
D_{r}=0.8 M^{1 / 3}
$$

where; $D_{r}$ is the crater diameter in metres and $M$ is the explosive mass in kilograms TNT. It can be seen from Figure 6 that this equation does not correlate with the physically obtained results of Ambrosini et al., (2002) as well as the numerical results obtained here. 


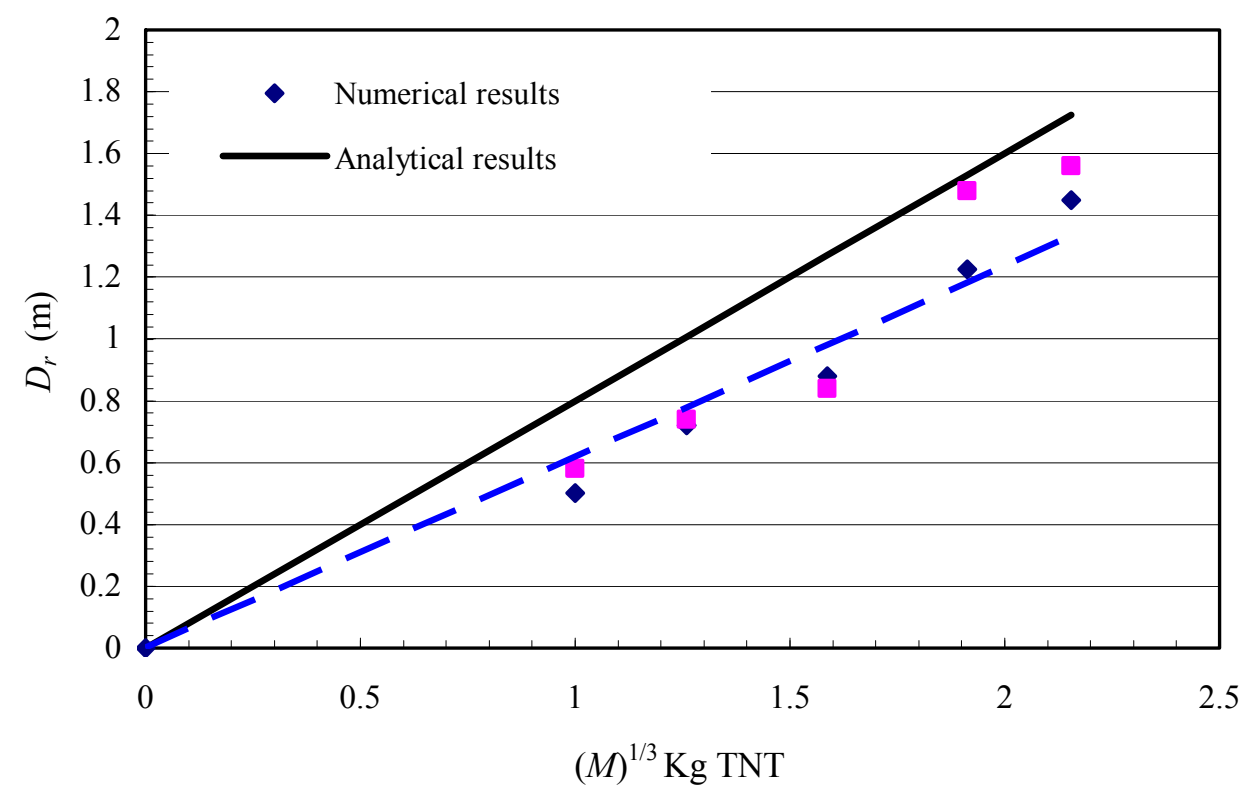

Figure 5. Crater diameters produced by explosions NUMERICAL SIMULATIONS OF LARGE EXPLOSIVE CHARGES

The experimental tests reported by Ambrosini et al., (2002) inevitably used only small explosive charges. Accordingly further numerical solutions have been established for the crater dimensions created from the TNT charges from $20 \mathrm{~kg}$ to $640 \mathrm{~kg}$ placed directly on the ground surface to simulate more closely the situations of practical interest discussed in the introduction. All the material models, material properties and the analysis procedures for these larger charge masses are the same as those defined for the small explosive charges considered above except that the soil mesh area is taken as $30 \mathrm{~m} \times 30$ $\mathrm{m}$. The numerical results for the crater diameter as a result of using large quantities of explosive charge are presented in Table 5.

Table 5: The numerical results for the crater diameter formed from large surface explosions

\begin{tabular}{|c|c|}
\hline TNT Charge mass $\boldsymbol{M}(\mathbf{k g})$ & True Crater Diameter $\boldsymbol{D}_{\boldsymbol{r}}(\mathbf{m})$ \\
\hline 20 & 1.84 \\
\hline 40 & 1.96 \\
\hline 80 & 2.23 \\
\hline 160 & 2.79 \\
\hline 320 & 3.14 \\
\hline 640 & 5.17 \\
\hline
\end{tabular}

These results in conjunction with the numerical results for small charges are presented graphically in Figure 6 with the crater diameter $D_{r}$ again plotted as a function of the cubic root of the explosive charge $M$. In this figure the best-fit line is also shown for the whole range of explosive charges and its equation is given by: 


$$
D_{r}=0.55679 M^{1 / 3}
$$

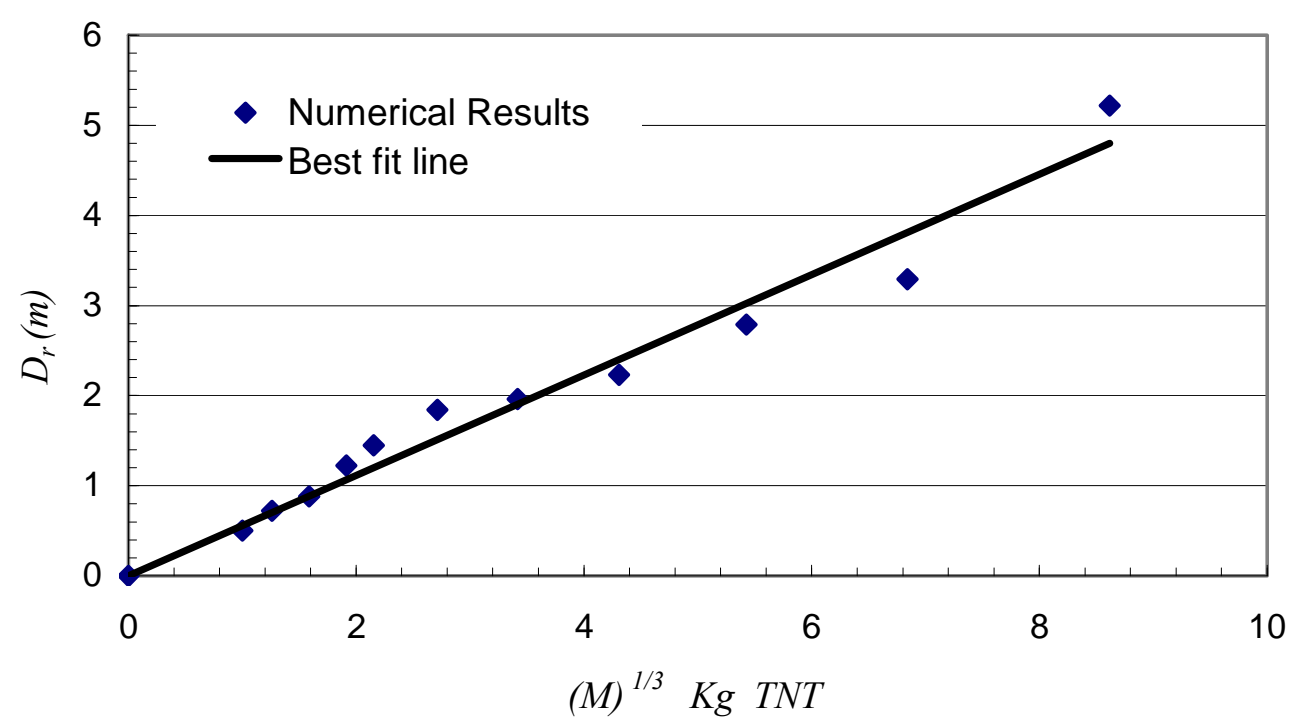

Figure 6. Numerical results of crater diameter for surface explosions

Equation (12) is considered preferable to Equation (10); since it is obtained over a much wider range of explosive charges. The difference between the two equations at small charges is relatively small. Equation (12) can therefore be recommended for prediction of the crater diameter formed from surface explosions in soils similar to that used in its derivation. In order to increase the range of applicability of Equation (12), its applicability for prediction of crater diameter in clay soils with different densities is now investigated.

\section{INFLUENCE OF SOIL PROPERTIES ON SOIL EXPLOSION EFFECTS}

Ambrosini et al., (2004) investigated the effect of the elastic soil properties on the crater diameter resulting from surface explosions and it was found that variation of the shear modulus does not affect the dimensions of the crater significantly. Variation in crater development after the surface explosion gives an indication of the importance of representative changes in soil properties. Accordingly additional numerical investigations are being carried out by varying some of the soil properties. The effect of soil mass density has been investigated using the overall numerical model described above by considering a range of soil densities from $1300 \mathrm{~kg} / \mathrm{m} 3$ to $2000 \mathrm{~kg} / \mathrm{m} 3$. The results obtained are presented in Table 6: 
Table 6: The effect of soil density on crater diameter

\begin{tabular}{|c|c|c|c|}
\hline $\begin{array}{c}\text { TNT } \\
\text { Charge } \\
\text { mass } \\
\text { (kg) } \\
\end{array}$ & $\begin{array}{c}\text { True Crater Diameter } \\
\text { (m) } \\
\begin{array}{c}\text { Soil density of } 1300 \\
\text { kg/m }\end{array} \\
\end{array}$ & $\begin{array}{c}\text { True Crater Diameter } \\
\text { (m) } \\
\text { Soil density of } 1920 \\
\text { kg/m }\end{array}$ & $D_{r 1} / D_{r 2} \%$ \\
\hline 20 & 1.92 & 1.84 & $104.34 \%$ \\
\hline 40 & 2.10 & 1.96 & $107.14 \%$ \\
\hline 80 & 2.32 & 2.23 & $104.04 \%$ \\
\hline 160 & 2.82 & 2.79 & $101.1 \%$ \\
\hline 320 & 3.33 & 3.14 & $106.1 \%$ \\
\hline 640 & 5.22 & 5.17 & $101 \%$ \\
\hline
\end{tabular}

Table 6 demonstrates that the mass density variation of the soil does not influence significantly the results for the crater diameters. However, it will be necessary to investigate variation of all the soil parameters before more generalized conclusions can be made. Therefore, Equation (12) can be used for prediction of the crater diameter in clay soils independent of density, but with properties otherwise as defined in Table 1

\section{CONCLUSIONS}

This paper presents a fully coupled numerical analysis of air-soil-explosion interaction. The analysis procedures and the material models in the fully coupled analysis are validated by comparison with physical tests. Good agreement is obtained between them. Further numerical studies have been performed using the fully coupled model to simulate the effects of large explosive charges.

Comparing to previous work it is found that Abaqus/Explicit is able to simulate correctly the crater formation resulting from the surface explosions. The Arbitrary Lagrange Euler Coupling formulation (ALE) has been shown to be suitable for the solution of numerical problems associated with mesh tangling and element distortion from the large deformation within the target region which can be existent in a pure Lagrangian formulation. It has been demonstrated that the cap model is extremely effective for predicting blast wave propagation through a clay soil. Results obtained using the cap model along with the JWL equation of state, compared extremely well with the results from the experimental field tests. Based on this experience the cap model should also be able to simulate the blast response of sandy soils.

Based on the full set of numerical results, a new equation is presented for the prediction of crater diameter produced by explosions in clay soils taking the variation of soil density into account. This demonstrates that a simple linear equation can be used to predict the crater dimensions as a function of the explosive charge mass. Further studies are underway to investigate the crater formation in different soils considering parametric variation of all soil properties. 


\section{REFERENCES}

ABAQUS ANALYSIS MANUAL, ABAQUS Analysis User's Manual, Version 6.4, Published by Hibbitt, Karlsson And Sorensen Inc. USA, 2004..

ABAQUS EXAMPLE MANUAL, ABAQUS Example Problems Manual, version 6.4, Published by Hibbitt, Karlsson And Sorensen Inc. USA, 2004.

ABAQUS THEORY MANUAL, ABAQUS Theory Manual, Version 6.4, published by Hibbitt, Karlsson And Sorensen Inc. USA, 2004

AMBROSINI, D., LUCCIONI, B. \& DANESI, R. Influence of the Soil Properties on Craters Produced By Explosions on the Soil Surface, Mec'anica Computational, XXIII, 571-590, 2004.

AMBROSINI, R. D., LUCCIONI, B. M., DANESI, R. F., RIERA, J. D. \& ROCHA, M. M. Size of craters produced by explosive charges on or above the ground surface. Shock Waves, 12, 69-78, 2002

BATCHELOR, G. K. An Introduction to Fluid Dynamics, Cambridge University Press; New Edition, 2000

BRAID, M. P. \& BERGERON, D. Experimental Investigation and Analysis of the Effects of Anti-Personnel Landmine Blasts. DRES SSP 2001-188. Defence Suffield Publication, Canada, 2001.

BULL, J. W. \& WOODFORD, C. H. Camouflets and their effects on runway supports. Computer and Structures, 69, 695-706, 1998

COOPER, P. W. Explosives Engineering, Wiley-VCH, Inc., 1997.

DRUCKER, D. C., \& PRAGER W. Soil Mechanics and Plastic Analysis or Limit Design Quarterly of Applied Mathematics, 10, 157-165, 1952

ELLIOT, C. L., MAYS, G. C. \& SMITH, P. D., The protection of buildings against terrorism and disorder, Proceedings of Institution of Civil Engineers, Structures and Buildings, Vol. 94, Issue 3, 1992

FAIRLIE, G. \& BERGERON, D. Numerical Simulation of Mine Blast Loading on Structures 17th Military Aspects of Blast Symposium, Las Vegas, Nevada, 2002.

FORMBY, S. \& WHARTON, R. K. Blast Characteristics and TNT Equivalence Values for Some Commercial Explosives Detonated at Ground Level. Journal of Hazardous Materials, 50, 183-198, 1996

GRUJICIC, M., PANDURANGAN, B. \& CHEESEMAN, B. A., A Computational Analysis of Detonation of Buried Mines. Multidiscipline Modelling in Materials and Structures, 2, 363-387, 2006

HODGE, B. K. \& KOENIG., K. Compressible Fluid Dynamics, Prentice Hall, Englewood Cliffs, New Jersey, 1995.

HU, Y. \& RANDOLPH M. F., A Practical Numerical Approach for Large Deformation Problems in Soil, International Journal for Numerical and Analytical Methods in Geomechanics, 22, 327-350, 1998

ITURRIOZ, I. \& RIERA, J. D. Numerical study of the effect of explosive sources near the ground surface: crater formation. SMiRT16, Washington DC, 2001

KANARACHOS, A. \& PROVATIDIS, C. H. Determination of buried structure loads due to blast explosions. Structures under Shock and Impact, V, 95-104, 1998

KINNEY, G. F. \& GRAHAM, K. J. Explosive shocks in air, New York, Springer Verlag, 1985. 
LEE, E., FINGER, M. \& COLLINS, W., JWL equations of state coefficient for high explosives., Lawrence Livermore Laboratory, Livermore, Calif, UCID-16189, 1973

LEE, E. L., HORNIG, H. C. \& KURY., J. W. Adiabatic Expansion of High Explosive Detonation Products. Lawrence Radiation Laboratory, University of California,UCRL- 50422, 1968.

LIU, G. R. \& LIU, M. B. Smoothed Particle Hydrodynamics: A Mesh free Particle Method, Singapore, World Scientific Publishing Company Pte. Ltd. 2003

MIZUNO, E. \& CHEN, W. F., Nonlinear Analysis in Soil Mechanics Theory and Implementation, Elsevier Science Publishers B.V, 1990

PERSSON, P. A., HOLMBERG, R. \& LEE, J. Rock blasting and explosives engineering, USA, CRC Press, 1994.

SMITH, P. D. \& HETHERINGTON, J. G., Blast and Ballistic Loading of Structures, Butterworth and Heinemann Ltd Oxford, 1994

WANG, J. Simulation of Landmine Explosion Using LS-DYNA3D Software: Benchmark Work of Simulation of Explosion in Soil and Air, DSTO-TR-1168, 2001.

ZHONGQI, W., HONG, H. \& YONG, L., A three-phase soil model for simulating stress wave propagation due to blast loading., International Journal for Numerical and Analytical Methods in Geomechanics, 28, 33-56, 2004 